\title{
On the sense of taste in two Malagasy primates (Microcebus murinus and Eulemur mongoz)
}

\author{
G.Hellekant, C.M.Hladik', V.Dennys ${ }^{1}$, B.Simmen', T.W.Roberts, D.Glaser ${ }^{2}$, \\ G.DuBois ${ }^{3}$ and D.E.Walters ${ }^{4}$
}

University of Wisconsin, Department of Animal Health and Biomedical

Sciences, and Wisconsin Regional Primate Center, Madison, WI 53706, USA,

${ }^{I}$ CNRS, Laboratoire d'Ecologie Generale, 4 Avenue de Petit Chateau, 91800

Brunoy, France, ${ }^{2}$ Anthropological Institute, University Zürich-Irchel,

CH-8057, Zarich, Swizzerland, ${ }^{3}$ Corporate Research and Development, The

Coca Cola Company, Atlanta, GA 30301 and ${ }^{4}$ Department of Biological

Chemistry, The Chicago Medical School, 3333 Green Bay Road, North

Chicago, IL 60064-3095, USA

\begin{abstract}
The relationship between phylogeny and taste is of growing interest. In this study we present recordings from the chorda tympani proper (CT) nerve of two lemuriforme primates, the lesser mouse lemur (Microcebus murinus) and the mongoose lemur (Eulemur mongoz), to an array of taste stimuli which included the sweeteners acesulfame-K, alitame, aspartame, D-glucose, dulcin, monellin, neohesperidin dihydrochalcone (NHDHC), sacharin, sodium superaspartame, stevioside, sucralose (TGS), sucrose, suosan, thaumatin and xylitol, as well as the non-sweet stimuli $\mathrm{NaCl}$, citric acid, tamnin and quinine hydrochloride. In $M$.murinus the effects of the taste modifiers gymnemic acid and miraculin on the CT response were recorded. Conditioned taste aversion (CTA) experiments in M.murinus and two-bottle preference (TBP) tests in E.mongoz were also conducted. We found that all of the above tastants except thaumatin elicited a CT response in both species. The CTA technique showed that M.murinus generalized from sucrose to monellin but not to thaumatin. The intake of aspartame, ranging in concentration from 0.1 to $30 \mathrm{mM}$ was measured in $E$.mongoz with TBP tests. At no concentration did we see a preference, but there was a significant rejection of 10 and $30 \mathrm{mM}$ aspartame $(P<0.025)$. Miraculin had no effects on the CT response to acids, and gymnemic acid did not selectively suppress the CT response to sucrose or that of any other sweeteners. The absence of ability to taste thaumatin in these species supports the dichotomy between catarthine and non-catarrhine species. The difference in results with thaumatin and monellin indicate that their sweet moieties are not identical. It also points to a phylogenetic difference in taste within the prosimian group. Further, the results with aspartame indicate that the perception of sweetness from aspartame is limited to catarthine species. Finally, neither miraculin nor gymnemic acid exhibit the same taste modifying effects in lemuriformes as they do in hominoidea. Thus the results with gymnemic acid and miraculin corroborate those obtained earlier in other prosimians.
\end{abstract}

\section{Introduction}

Taste is the link between food and diet. The sense of taste may control, more than any other external sense, including smell, the ecological niche of a species. Thus there may be differences in the sense of taste not only between fructivorous and insectivorous forms, but also among species within these groups: what is palatable to one species may be unpalatable or have no taste to another.

However, an increasing number of observations indicate that many taste differences are phylogenetically related and not random. The taste modifying protein miraculin is a striking example; in humans it adds a sweet taste to acid that early on was thought to occur in all mammals. It was therefore surprising when Diamant et al. (1972) found that it had no effect in rats, although the effects were observed in recordings from humans and the simian Cercopithecus monkey. Later studies (Hellekant et al., 1974, 1976, 1981; 
Brouwer et al., 1983) showed that when miraculin is applied to the tongues of non-simian primates, it does not exert the same taste modifying effect as in humans; its effects are limited to simian primates (cf. Hellekant and van der Wel, 1989).

Experiments with the sweet proteins monellin and thaumatin showed that the sense of taste in the simian group, traditionally divided into a platyrrhine and catarrhine group, is not uniform. Studies by Hellekant $e t$ al., 1976, 1981), Glaser and Hellekant (1977), and Glaser et al. (1978) demonstrated that monellin and thaumatin have no sweet taste to platyrrhine primates, although they taste sweet to catarrhine primates.

Similar results obtained with monellin in prosimians (Glaser $e$ t al., 1978) suggest that within the prosimian group, the sense of taste differs. Two bottle preference (TBP) tests showed a clear preference for monellin in the Lemuridae prosimians E.mongoz and a slight preference in Varecia variegatus, while the related M.murinus and all other prosimian species tested showed no preference (Glaser et al., 1978). Electrophysiological results from Tupaia glis, Nycticebus coucang and Galago senegalensis corroborated the behavioral ones, when monellin was found not to elicit a taste response in these nonlemuride prosimians (Hellekant et al., 1981).

A taste response to monellin, but not to thaumatin, in the same species suggests that the moieties on monellin and thaumatin that determine their sweet taste are different. This is an important finding from two points of view. First, it has been speculated that the sweet moiety of monellin and thaumatin is the same (e.g. van der Wel and Bel, 1978, 1980; Iyengar et al., 1979) and second, the difference between monellin and thaumatin suggests that there are phylogenetic differences in taste not only between simians (cf. Hellekant and Ninomiya, 1991) but also prosimians. These possibilities argue for an electrophysiological study in lemuriformes, which, supplemented with behavioral experiments, could answer some phylogenetic questions about them. It would also supply new data on the physiology of taste in species not studied earlier.

Although the species M.murinus was our main experimental animal, we also included E.mongoz, as our earlier work (Glaser et al., 1978) showed that it liked monellin.

\section{Materials and methods}

\section{Animals}

All M.murinus were from a colony kept on an artificial 8 month cycle of long days/short nights and 4 months of short days/long nights (Petter-Rousseaux, 1980) at the Laboratoire d'Ecologie Generale, Brunoy, France. The E.mongoz used for electrophysiology was housed in an outside cage at Brunoy, while the two E.mongoz used for two-bottle preference (TBP) tests were housed under controlled climatic conditions.

\section{Surgery}

In M.murinus the anesthesia and surgery have described earlier (Hellekant $e$ al., 1993). One male E.mongoz, weighing $2.6 \mathrm{~kg}$, was injected i.m. with $25 \mathrm{mg}$ ketamine and $0.5 \mathrm{mg}$ acepromazine to induce anesthesia prior to surgery. The anesthesia was maintained with i.v. pentobarbital sodium at a concentration of $13.5 \mathrm{mg} / \mathrm{ml}$. A polyethylene catheter was inserted between two cartilages of the trachea to facilitate respiration. Heart rate was monitored during the experiments. Isotonic $5 \%$ glucose solution was administered i.v. in E.mongoz in a dose of $1 \mathrm{ml} / 100 \mathrm{~g}$ body wt for each hour of anesthesia. 
The right chorda tympani proper (CT) nerve was approached through an incision along the mandibular angle between the rostral lobes of the parotid gland and the mandibular bone. First, the tissue attached to the mandibular angle was sectioned, and then blunt dissection was used to follow the caudo-medial side of the pterygoid muscle down to its origin at the pterygoid plate of the skull and to the CT. The CT enters the bulla tympani close to the lateral face of the medial pterygoid muscle; it is surrounded by a small amount of fatty tissue and can be dissected peripherally all the way until it joins the lingual proper nerve. In three M.murinus the nerve was embedded in the muscle and in two it was found lateral to the muscle. In the E.mongoz the nerve was found at the lateral margin of m.pterygoideus. After the recording period the wound was closed with 5-0 ethilon and the tracheal wound closed with $10-0$ nylon.

Conditioned taste aversion (CTA) test

CTA tests were performed in seven individuals of M.murinus divided into two groups, using the same procedure as in an earlier study (Hellekant et al., 1993). In summary, $200 \mathrm{mM}$ sucrose solution was used as conditioning stimulus followed by injection of $\mathrm{LiCl}$. During the tests, the animals were offered $50 \mathrm{mM}$ and $200 \mathrm{mM}$ sucrose, $0.06 \%$ thaumatin $0.02 \%$ monellin and water in the animals' normal food device, which consisted of a plastic tray with six compartments around a central cup. After 20 min the consumption of each solution was measured. The tests were repeated once a night for 32 nights $(n=32)$. The results were the same in both groups. However, since the circumstances with regard to the time for the experiment, presentation of solutions etc. were not identical, the numerical data reported here are from the latter group.

\section{Two-bottle preference}

One male and one female E.mongoz, housed together, were used for TBP tests. The intake of water and either $0.1,0.4,0.5,0.6,0.8,1.10$ or $30 \mathrm{mM}$ aspartame was measured overnight. The bottles were switched from right and left side randomly.

\section{Recording apparatus}

The overall nerve impulse activity was recorded between a silver wire in contact with the CT nerve and a silver plate connected to the wound. The nerve impulses were amplified with a PAR 113 amplifier, monitored over a loudspeaker and an oscilloscope, and fed into a recorder (Gould ES 2000). They were also integrated using an absolute value circuit integrator. The type of stimulus used and the stimulus duration were recorded as a binary coded signal. In addition an IBM PC-AT with a DAS-Keithley interface was used for storing and numerical processing of each response (Hellekant $e t$ al., 1991).

\section{Stimulation apparatus}

The surface of the tongue was stimulated with a portable version of the 'Taste-O-Matic' system (Hellekant et al., 1980). It delivers 12 solutions at given intervals over a predetermined time and under conditions of constant flow and temperature. The interval between each stimulation was $36 \mathrm{~s}$ and each stimulation lasted for $6 \mathrm{~s}$.

\section{Test substances and procedure}

The sweeteners and their concentrations used for the electrophysiological experiments are listed in Table I. For comparison, the following non-sweet stimuli were used: 0.04 
Tabłe I.

\begin{tabular}{|c|c|c|c|}
\hline Compound & Concentration (mM) & Potency in human & Reference \\
\hline Acesulfame-K & 3.5 & $125 x$ & \\
\hline Aspartame & 3.4 & $125 x$ & Mazur et al. (1969) \\
\hline Cyclamate- $\mathrm{Na}$ & 23 & $24 \times$ & \\
\hline D-glucose & 750 & $0.74 \times$ & \\
\hline Dulcin & 2.2 & $200 x$ & \\
\hline NHDHC & 680 & $480 x$ & \\
\hline Saccharin-Na & 1.6 & $300 x$ & \\
\hline Stevioside & 0.65 & $190 x$ & \\
\hline Sucralose (TGS) & 1 & $500 \times$ & $\begin{array}{l}\text { Hough and Khan (1978) } \\
\text { Higginbotham (1983) }\end{array}$ \\
\hline Sucrose & $\begin{array}{r}10 \\
42 \\
100 \\
300\end{array}$ & $1 \times$ & \\
\hline Suosan & 2.1 & $350 x$ & Petersen and Müller (1948) \\
\hline Xylitol & 750 & $0.8 \times$ & \\
\hline Monellin & 0.02 & $3000 x$ & \\
\hline Thaumatin & $\begin{array}{l}0.01 \\
0.02\end{array}$ & $3000 x$ & Iyenga et al. (1979) \\
\hline Alitame & 0.28 & $2200 x$ & Brennan and Hendrick (1983) \\
\hline Super-Aspartame & $\begin{array}{l}0.063 \\
0.127\end{array}$ & $3900 \times$ & Tinti and Nofre (1984) \\
\hline
\end{tabular}

$\mathrm{M}$ citric acid, $0.1 \mathrm{M} \mathrm{NaCl}$ and $0.01 \mathrm{M}$ quinine hydrochloride. In one M.murinus and the E.mongoz the taste nerve responses to $7.5 \times 10^{-5}$ and $2.0 \times 10^{-4} \mathrm{M}$ tannic acid were also recorded. All but one compound were dissolved in artificial saliva (Hellekant $e t$ al., 1985); the exception, quinine hydrochloride, was dissolved in distilled water for solubility reasons. Artificial saliva was used as tongue rinse between stimulations. In each animal the sequence of stimuli was repeated at least three times. Gymnemic acid, $3 \mathrm{mg}$ in one $\mathrm{ml} 0.01 \mathrm{M} \mathrm{NaHCO}$ (Hellekant et al., 1985), was applied to the tongue of one M.murinus for $3 \mathrm{~min}$. Finally, in another M.murinus, miraculin, $3 \mathrm{mg}$ in one $\mathrm{ml}$, was applied to the tongue for $3 \mathrm{~min}$.

\section{Data analysis}

The parameters measured on each summated recording have been defined and described in an earlier study (Hellekant et al., 1991). The CTA data were analyzed with ANOVA and the TBP data with ANOVA (analysis of covariance).

\section{Results}

\section{Eulemur mongoz}

Electrophysiology. Figure 1 shows a series of summated responses from the CT to stimulation with 17 of the compounds listed under Materials and methods. The most interesting finding is that aspartame and monellin gave responses. The response to aspartame (third from left) is similar to the one in M.murinus (Figure 2) with a relatively slow rise to 


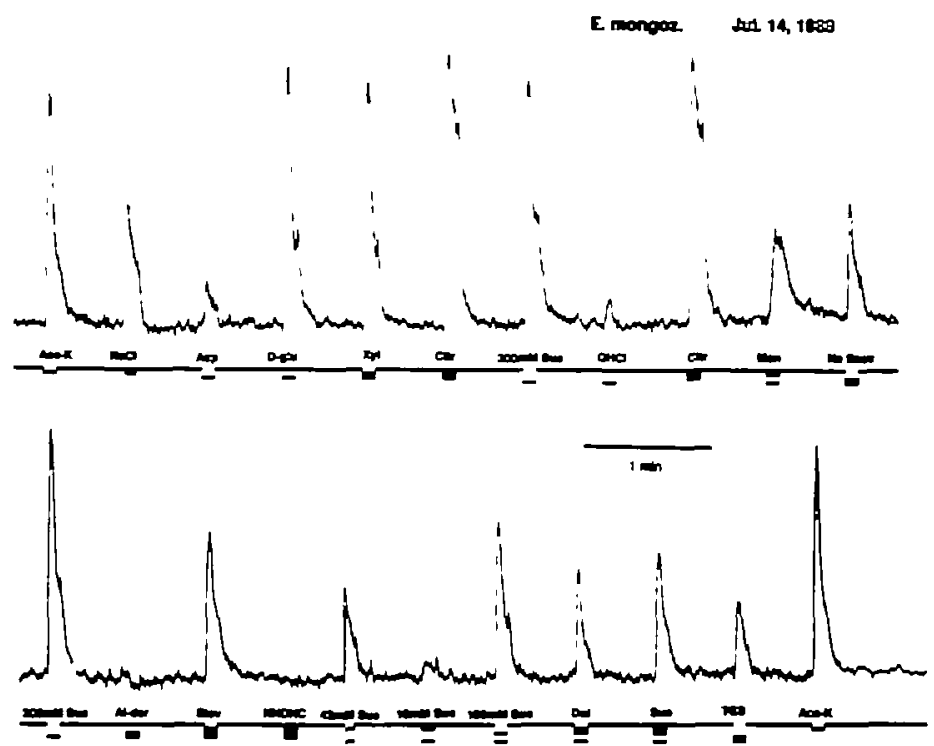

Fig. 1. The summated response from $E$.mongoz to stimulation of, from top left, $3.5 \mathrm{mM}$ acesulfame-K, $0.1 \mathrm{M}$ $\mathrm{NaCl}, 3.4 \mathrm{mM}$ aspartame, $0.75 \mathrm{M} \mathrm{D}-$ glucose, $0.75 \mathrm{M}$ xylitol, $0.04 \mathrm{M}$ citric acid, $0.3 \mathrm{M}$ sucrose, $0.01 \mathrm{M}$ quinine hydrochloride, $0.04 \mathrm{M}$ citric acid, $0.02 \%$ monellin, $1.6 \mathrm{mM} \mathrm{Na}$-sacharine, $0.3 \mathrm{M}$ sucrose, $0.28 \mathrm{mM}$ of alitame, $0.65 \mathrm{mM}$ stevioside, 42,10 and $100 \mathrm{mM}$ sucrose, $2.2 \mathrm{mM}$ dulcin, $2.1 \mathrm{mM}$ suosan, $1 \mathrm{mM}$ sucralose (TGS) and $3.5 \mathrm{mM}$ acesulfame-K. The nerve activity was recorded while the flow over the tongue was switched between artificial saliva and the stimuli indicated by the bottom trace.

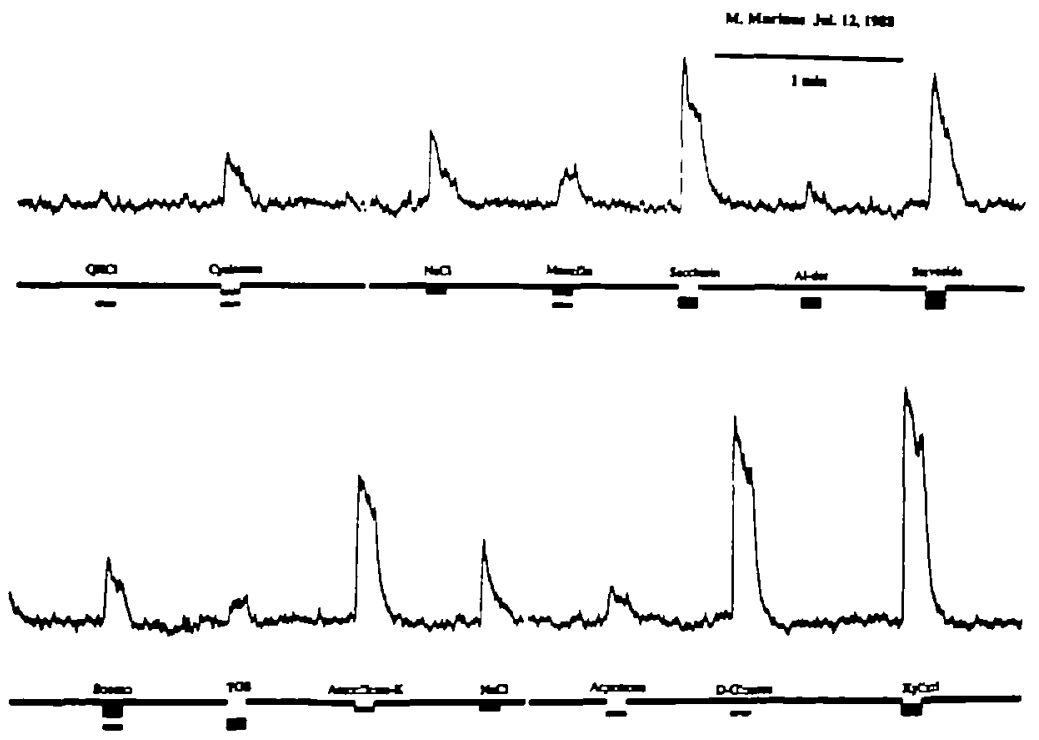

Fig. 2. Summated chorda tympani nerve recordings from $M$. murinus during stimulation with, from the top left, $0.01 \mathrm{M}$ quinine, $23 \mathrm{mM}$ Na-cyclamate, $100 \mathrm{mM} \mathrm{NaCl}, 0.02 \%$ monellin, $1.6 \mathrm{mM} \mathrm{Na}$-saccharine, $0.28 \mathrm{mM}$ alitame, $0.65 \mathrm{mM}$ sevioside, $2.1 \mathrm{mM}$ suosan, $1 \mathrm{mM}$ sucralose (TGS), $3.5 \mathrm{mM}$ acesulfame-K, $0.1 \mathrm{M} \mathrm{NaCl}, 3.4 \mathrm{mM}$ aspartame, $0.75 \mathrm{M} \mathrm{D}$-glucose and $0.75 \mathrm{M}$ xylitol. The nerve activity was recorded while the flow over the tongue was switched between artificial saliva and the stimuli indicated by the bottom trace. 


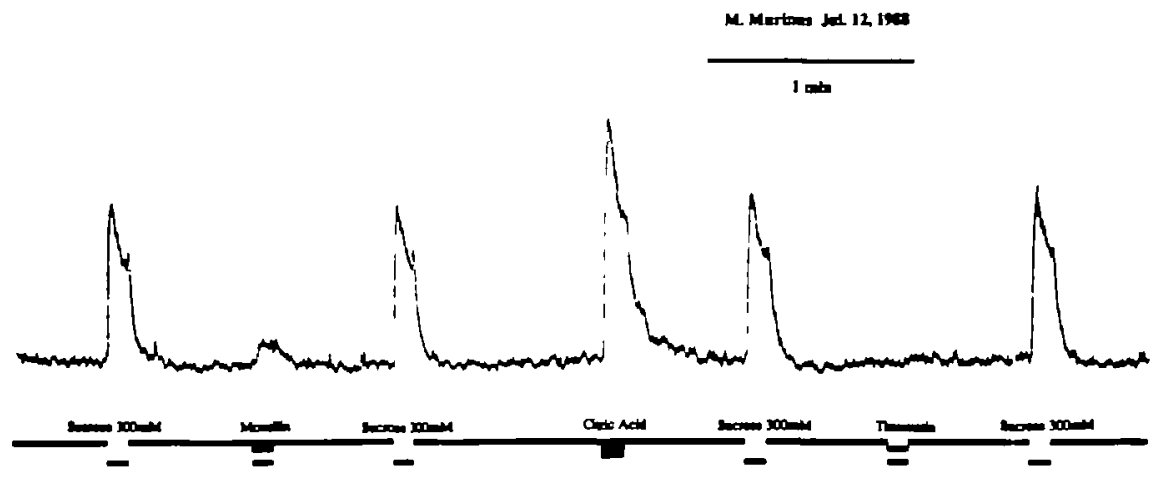

Fig. 3. The summated responses in a M.murinus to $0.02 \%$ monellin, $0.06 \%$ thaumatin, $0.3 \mathrm{M}$ sucrose and $0.04 \mathrm{M}$ citric acid.

maximum. The response to monellin is quite large and shows the characteristics found in the response to monellin in other species; a slow increase of nerve activity and a long lasting decline after stimulation. Notable is that $10 \mathrm{mM}$ sucrose elicited a nerve response, which suggests that E.mongoz is at least as sensitive to sucrose as M.murinus (Hellekant et al., 1993). Thaumatin (not shown) did not give a response, and also there was no response to either alitame or NHDHC (Figure 1). However, because our electrophysiological data in E.mongoz originates from only one animal, conclusions related to an absence of a taste response are tentative.

Two-bottle preference test. We measured the intake of aspartame with TBP tests of concentrations ranging from $0.1-30 \mathrm{mM}$. At no concentration of aspartame did we see a preference, however, we did observe a significant rejection of 10 and $30 \mathrm{mM}$ aspartame $(P<0.025)$.

\section{M.murinus}

Electrophysiology. Figure 2 presents a series of recordings from the CT nerve in M.murinus; quinine hydrochloride, cyclamate, $\mathrm{NaCl}$, monellin, saccharine, stevioside, suosan, acesulfame-K, aspartame, D-glucose and xylitol all gave robust nerve response. On the other hand, responses to the sweeteners sucralose (TGS), aspartame, NHDHC (not shown) and alitame were small but significant.

Figure 3 is included to exhibit the difference in gustatory effects of monellin and thaumatin in M.murinus. Monellin gave an unquestionable nerve response, but there was no response to thaumatin, although we used a three times higher concentration of thaumatin than monellin. The absence of a thaumatin response is particularly surprising when one considers that in humans thaumatin is more potent than monellin. As can be seen in Figure 3 , the thaumatin and the monellin stimulations were preceded and followed by stimulations with sucrose. The absence of cross-adaptation between thaumatin and sucrose was expected, while the absence of cross-adaptation between monellin and sucrose could have been caused by a shorter lasting effect of monellin than expected. The response to tannic acid was recorded in one animal, of which the response to the lower concentration $\left(7.5 \times 10^{-5} \mathrm{M}\right)$ was doubtful but the higher concentration $\left(2.0 \times 10^{-4} \mathrm{M}\right)$ elicited a significant response. 
Table II. The parameters measured on each summated recordings. They are defined as follows: $N$ is defined as the total number of stimulations with a given taste stumulus; Max, the maximum amplitude of the response; Area, the surface area under the response; Delay, the time between the onset of the stimulus flow and the response (the moment for onset of response is defined as the first point $10 \%$ larger than the baseline); Slope ( $\mathrm{d} y / \mathrm{d} r$ ), a measure of the change in magnitude of nerve activity with time during stimulation; Rise, time between onset of the current that opens the valve and maximum response amplitude; Tonic, the amplitude of the tonic activity during stimulation (determined $4.5 \mathrm{~s}$ after onset of stimulation as a running average over the next $500 \mathrm{~ms}$ ); Resume, time from the closing of the valve to the point of return of nerve activity to prestimulation level (i.e. the baseline activity).

\begin{tabular}{|c|c|c|c|c|c|c|c|c|}
\hline Solution & $N$ & $\operatorname{Max}{ }^{2}$ & Area & Delay (ms) & Slope" & Rise (ms) & Tonic* & Resume (ms) \\
\hline Acesulfame-K & 4 & 156 & 2124 & 350 & 11 & 1320 & 62 & 3866 \\
\hline SD & & 8 & 73 & 70 & 3 & 297 & 5 & 673 \\
\hline Alitame-der & 7 & 25 & 282 & 771 & 4 & 851 & 5 & 1806 \\
\hline $\mathrm{SD}$ & & 6 & 43 & 210 & 2 & 461 & 1 & 766 \\
\hline Aspartame & 6 & 38 & 534 & 430 & 3 & 1093 & 9 & 1817 \\
\hline $\mathrm{SD}$ & & 1 & 22 & 49 & 1 & 759 & 1 & 832 \\
\hline D-Glucose & 9 & 220 & 3719 & 320 & 17 & 956 & 95 & 3938 \\
\hline SD & & 7 & 88 & 20 & 2 & 140 & 3 & 625 \\
\hline Dulcin & 6 & 161 & 2181 & 383 & 13 & 963 & 68 & 6427 \\
\hline SD & & 9 & 190 & 37 & 1 & 100 & 10 & 1284 \\
\hline Monellin & 7 & 41 & 488 & 1057 & 3 & 1914 & 13 & 3117 \\
\hline SD & & 7 & 100 & 453 & 1 & 957 & 4 & 947 \\
\hline $\mathrm{Na}$ Cyclamate & 9 & 54 & 766 & 458 & 5 & 791 & 12 & 2816 \\
\hline SD & & 8 & 80 & 38 & 1 & 150 & 1 & 1537 \\
\hline Na Saccharine & 7 & 148 & 2310 & 374 & 14 & 786 & 48 & 5082 \\
\hline SD & & 10 & 259 & 43 & 3 & 187 & 7 & 2161 \\
\hline NHDHC & 3 & 34 & 484 & 1033 & 1 & 1533 & 12 & 3900 \\
\hline SD & & 10 & 136 & 195 & 0 & 419 & 5 & 1866 \\
\hline Stevioside & 7 & 128 & 1992 & 451 & 10 & 1000 & 44 & 3126 \\
\hline SD & & 8 & 179 & 13 & 1 & 150 & 6 & 501 \\
\hline Sucrose & 30 & 187 & 5195 & 301 & 15 & 968 & 77 & 4022 \\
\hline SD & & 24 & 356 & 72 & 4 & 175 & 14 & 794 \\
\hline Suosan & 4 & 65 & 898 & 560 & 4 & 1030 & 16 & 1565 \\
\hline SD & & 12 & 118 & 33 & 1 & 127 & 2 & 390 \\
\hline Super-APM & 3 & 14 & 99 & 700 & 11 & 327 & 3 & 967 \\
\hline SD & & 2 & 18 & 100 & 10 & 290 & 2 & 200 \\
\hline TGS & 3 & 42 & 473 & 607 & 11 & 1507 & 10 & 2573 \\
\hline$S D$ & & 3 & 51 & 10 & 2 & 1640 & 1 & 170 \\
\hline Thaumatin & 4 & 9 & 68 & 3840 & 2 & 3140 & 4 & 870 \\
\hline SD & & 3 & 17 & 0 & 0 & 40 & 1 & 730 \\
\hline Xylitol & 8 & 244 & 4920 & 283 & 19 & 915 & 111 & 3975 \\
\hline SD & & 10 & 241 & 32 & 1 & 29 & 6 & 647 \\
\hline Citre Acid & 14 & 251 & 4167 & 350 & 20 & 924 & 95 & 9236 \\
\hline SD & & 28 & 473 & 63 & 4 & 214 & 12 & 1157 \\
\hline $\mathrm{NaCl}$ & 15 & 100 & 1147 & 360 & 9 & 764 & 28 & 3927 \\
\hline SD & & 10 & 236 & 34 & 2 & 155 & 6 & 1015 \\
\hline $\mathrm{QHCl}$ & 10 & 68 & 1071 & 1954 & 9 & 310 & 22 & 2700 \\
\hline SD & & 6 & 102 & 1671 & 7 & 50 & 5 & 1667 \\
\hline
\end{tabular}

arbitrary units. 
In Table II are given data which describe the responses of M.murinus to many of the stimuli used. Definitions and application of these parameters to describe the intensity and temporal characteristics of sweeteners have been reported in an earlier study (Hellekant et al., 1991). Mean data from four animals are included except for acesulfame-K, which was used in two animals. Some of the features of interest in Table II are: (i) the maximum amplitudes and surface areas of responses are highly correlated ( $r=0.957$, Pearson), as one would expect; (ii) no response to thaumatin was observed, while notable responses to monellin and aspartame were recorded; (iii) the time between onset of a stimulation and the nerve response as well as maximum were considerably longer for monellin than for any other sweetener; and (iv) a long delay in the response to quinine was observed.

Conditioned taste aversion test. The taste of thaumatin and monellin was further studied with the CTA technique. After conditioning, using sucrose as the conditioning stimulus, the animals avoided the monellin solution. The mean intake (in $\mathrm{ml}$ ) of water was 1.366 (SD 2.517), monellin 0.419 (SD 0.889), $200 \mathrm{mM}$ sucrose 0.094 (SD 0.125), $50 \mathrm{mM}$ sucrose 0.403 (SD 1.473) and thaumatin 0.975 (SD 2.093). A $t$-test applied to the data gave a $P$-value $<0.002$ for $200 \mathrm{mM}$ sucrose, $P<0.05$ for $50 \mathrm{mM}$ sucrose and $P<0.01$ for monellin ( $n=32$, paired sample $t$-test applied to the difference between solution and water). This indicates that the animals generalize the taste of sucrose to monellin.

This is in contrast to the result with thaumatin, which elicited neither a taste sensation, as judged by the nerve response, nor a sweet taste, as indicated by the results of the conditioned taste aversion tests $(P<0.88$ for the difference between thaumatin and water).

The effect of gymnemic acid and miraculin. Gymnemic acid, which in apes and humans, but not in other primates, abolishes or decreases the response to sweeteners, was applied to the tongue of one $M$.murinus for $3 \mathrm{~min}$. After application the responses to all stimuli except citric acid were suppressed. The most pronounced and longest suppression was a $50 \%$ decrease of the response to $\mathrm{NaCl}$, visible for at least $20 \mathrm{~min}$. On the other hand, responses to sucrose and the other sweeteners were much less affected. Thus $70 \mathrm{mM}$ sucrose, for example, gave a significant response after gymnemic acid. From this it is evident that gymnemic acid does not exert the same effects in M.murinus as it does in apes and humans; its effects in M.murinus resemble more those observed in non-primates.

After miraculin has been applied to the human tongue a sweet taste is added to the taste of sour compounds. In summated taste nerve recordings this effect is seen as an enhancement of the nerve response to acids (Brouwer $e t$ al., 1983). However, this effect has only been observed in simian primates (Hellekant and van der Wel, 1989). We applied miraculin in one M.murinus and did not record any effects on the responses to citric acid or any other stimulus.

\section{Discussion}

An increasing number of studies reveal species differences in taste. This is true not only among species in different classes (e.g. mammals and non-mammals), but also within the mammalian class (cf. Kare and Ficken, 1963; Jakinovich and Sugarman, 1989) or within the primate order (Hellekant et al., 1974, 1976; Glaser et al., 1978; Hellekant et al., 1981; Glaser et al., 1984; Hellekant et al., 1985, 1987; Hellekant and van der Wel, 1989; Hellekant et al., 1990). 
The results here show that monellin, but not thaumatin, elicits a taste in E.mongoz and M.murinus, and that this taste probably is sweet. The results with aspartame suggest that the same compound may elicit a different basic taste sensation in different species. Generally these results demonstrate the importance of choosing the appropriate animal model for humans (Hellekant and Ninomiya, 1991). They also suggest that the taste receptor for monellin is different from that of thaumatin (e.g. Hellekant, 1975; Jakinovich and Sugarman, 1989; Walters et al., 1991). Finally, these results have bearing on the phylogenetic questions approached in our earlier study (Glaser et al., 1978) in which we employed thaumatin as a tool to classify primates into Catarrhina and Platyrrhing. Here we discuss these questions with insights gained from the use of monellin, thaumatin, aspartame, gymnemic acid and miraculin.

\section{Monellin}

Monellin elicited a CT nerve response in both M. murinus and E.mongoz. The inevitable conclusion is that monellin must elicit a taste sensation in both species. The question is, what is the taste quality?

In the CTA experiments with M.murinus, we found a generalization from sucrose to monellin which indicates that monellin elicits a sucrose-like taste in M.murinus. This seems to contrast with the work of Glaser et al. (1978). However, it should be noted that M.murinus passes through a yearly cycle which strongly affects several biological parameters (Petter-Rousseaux, 1980; Perret, 1985), including its TBP threshold for sucrose. Simmen and Hladik (1988) found that this threshold varies between $28-45 \mathrm{mM}$ at one time of the year to $77-105 \mathrm{mM}$ at another time and questioned whether or not there is a seasonal variation in the ability of $M$. murinus to taste sucrose. Hellekant $e t$ al. (1993) observed with electrophysiological and CTA techniques that animals in both cycles were able to taste the lower sucrose concentrations. Consequently factors unrelated to their peripheral sweet taste sensitivity were responsible for the variation in TBP tests. It is possible that the M.murinus used by Glaser et al. (1978) tasted the sweetness of the $0.02 \%$ monellin and did not show this in their behavior.

With regard to E.mongoz, there are no reports of a seasonal cycle (Nowak, 1991) and its behavior reflects better its ability to taste. The electrophysiological results described here corroborate the earlier study (Glaser et al., 1978) which suggest that monellin has a sweet taste to E.mongoz. It should also be noted that the E.mongoz response to monellin was larger (Figure 1) than that of M.murinus (Figure 2), if the response to $\mathrm{NaCl}$ is used as standard.

The results with monellin may be applied to a phylogenetic question within Strepsirhini (or Prosimiae). The genus Microcebus was formerly assigned to the Lemuridae, but is now placed in the family Cheirogaleidae, which is considered being closely related to Lorisidae (Tattersall and Schwartz, 1975; cf. Nowak, 1991). This is interesting because both earlier TBP (Glaser et al., 1978) and electrophysiological (Hellekant et al., 1981) studies show that monellin does not taste sweet to at least two Lorisidae species, Nycticebus coucang and Loris tarigradus nycticeboides. Since both E.mongoz and M.murinus perceive monellin as sweet, the results suggest a closer relationship between Cheirogaleidae (M.murinus) and Lemuridae (E.mongoz) than between Cheirogalidae (M.murinus) and Lorisidae ( $N$.coucang and L.mycticeboides).

Further studies with other tastants may add data which could be useful in the above 
taxonomic discussions within Strepsirhini and in particular the lemuriforme group (e.g. Tattersall and Schwartz, 1975; Petter and Petter-Rousseaux, 1979; cf. Nowak 1991). It is also likely that future nerve recordings may show that monellin tastes sweet to other members of the lemuriforme infraorder, although our earlier TBP study does not give unequivocal support for this conclusion, except for V.wariegatus (Glaser et al., 1978).

\section{Thaumatin}

The absence of a taste nerve response and the results of the CTA tests to thaumatin suggest that it has no taste to E.mongoz and M.murinus. This supports our earlier conclusions (Glaser et al., 1978; Hellekant et al., 1981) of a clear difference between catarrhine species, which taste the sweetness of thaumatin, and non-catarthine species, to which E.mongoz and M.murinus belong, which are unable to do so.

\section{Thaumatin/monellin}

The conclusion that monellin tastes sweet and thaumatin lacks taste to M.murinus and E.mongoz is important from more than one point of view.

First, it suggests that the receptor-binding determinants on monellin differ from those of thaumatin. It is apparent that the taste receptors of M.murinus and E.mongoz do not make use of the same moiety on thaumatin and monellin. This should be taken into consideration when similarities of these molecules in the amino acid sequences, antigenicity or any other moiety are used to identify the moiety responsible for their sweet taste.

Second, it is difficult to reconcile the idea of only one sweet receptor type in primates (cf. Walters et al., 1991) with the findings here and earlier findings showing that to many primates both monellin and thaumatin taste sweet (cf. Hellekant et al., 1990). If one maintains that there is only one sweet receptor type in each primate species, an alternative conclusion is that this receptor differs from species to species.

However, it is also possible that differences in the secretory components found in the pores to taste buds may be the cause. It is well known that all taste pores show secretory components which surround the microvilli. The secretion is very resilient; $>1 \mathrm{~h}$ of rinsing with tap water or Ringer's solution does not expose the microvilli of the fungiform taste bud (Murray et al., 1972). Because we used animals under general anesthesia and rinsed the tongue continuously, the taste pore could not have been replenished by secretion from outside sources, e.g. the large salivary glands. The tastes pores of the vallate and foliate taste buds are more protected as they are situated in moats or folds. This points to a function for this secretion.

A recent study of rhesus monkey foliate papillae with gold-labeled thaumatin (Menco and Hellekant, 1993) suggests that the secretion plays a role for the taste of thaumatin. We found the gold-labeled thaumatin bound to the secretory substance inside the taste pores, even deep inside the pore, where the substance was surrounded by other nonlabeled structures. There was no consistent labeling of any other structure inside the tastebud pores, which included membranes of the taste-bud cell microvilli. Pre-incubation with unlabeled thaumatin prevented the labeling. We suggested that the secretory substance serves as an intermediate between stimuli and receptors, possibly involved in both stimulus removal and delivery. Thus differences in composition of the taste pore content may explain our findings. It is possible that a 'thaumatin component' is present in the taste pore of thaumatin tasting species that is missing in species which do not taste thaumatin. 
Finally, the conclusion that monellin tastes sweet and thaumatin lacks taste to M.murinus and $E$.mongoz raises the intriguing phylogenetic question as to why monellin tastes sweet to Malagasy prosimians (if the results from these two species apply to all lemuriformes) but not to other prosimians (Glaser et al., 1978; Hellekant et al., 1981). First, it can be mentioned that neither Thaumatococcus danielli nor Discoreophyllum cumminsii exist on Madagascar. Consequently the ability of lemuriformes to taste monellin cannot be explained in terms of a recent symbiotic relationship between a seed disperser and a fruit producing plant.

However, we propose an explanation that is based on an evolutionary symbiotic relationship. In the early Eocene period, when South America was still adjacent to the African plate, the first lemurs (genus Purgatorius) emerged. The different primate radiations that followed were synchronous with flowering plants bearing fruits. Many plants produced animal attracting compounds (usually sugars), so that their fruits were consumed; this contributed to their survival. In this context, the emergence of plant species bearing fruit with 'sugar mimics' is likely to occur (Hladik and Hladik, 1988).

The family (Menispermaceae) of the monellin producing D.cumminsii is more primitive than the family (Marantaceae) of the thaumatin producing T.daniellii. We propose that Menispermaceae developed monellin in parallel with the first lemurs. Later, after Madagascar's primates had been isolated from Africa, Marantaceae evolved in Africa together with the ability of African simians to taste its sweet substances. The plant species bearing fruits containing thaumatin appeared and were selected for.

\section{Aspartame}

In M.murinus and E.mongoz we recorded a taste nerve response to aspartame. Our TBP tests showed that aspartame had an aversive taste to E.mongoz; aspartame was not liked at any concentration and was rejected when the concentration was increased. This raised the question of what kind of taste quality aspartame elicits in these two species? Other earlier results (Glaser et al., 1992) show a similar reaction in M.murinus. These results suggest that, if aspartame has a sweet taste, an aversive component is present. It is possible that aspartame possesses taste qualities similar to those of saccharine. The taste of saccharine includes a bitter component which grows with concentration.

On the other hand, it is possible that aspartame did not taste sweet to E.mongoz and $M$. murinus at any concentration; this notion is supported by our electrophysiological data listed in Table II. We have observed (Hellekant et al., 1990; 1991; Hellekant and Walters, 1993) that temporal profiles of compounds are quite similar from species to species, provided the compound elicits the same taste. This is a statement open for critique, as we really do not know if, for example, acesulfame-K tastes sweet to a M.murinus; we can at most state that it tastes similar to sucrose.

A comparison between the data in Table II and similar data from other primates shows that the temporal profile (Hellekant et al., 1991) of the summated response to aspartame in M.murinus resembles more that of quinine than that of a sweetener. It has a longer delay, less steep slope and slower rise time than seen in primates to which it tastes sweet. Thus in Macaca mulatta, in which behavioral data show that aspartame tastes sweet (Hellekant, 1980), the delay and rise time are shorter, and the difference between tonic and phasic values larger (Hellekant et al., 1991) than observed here. The summated response in the gibbon, Hylobates lar (Hellekant $e t$ al., 1990), to which aspartame most 
likely tastes sweet, shows a somewhat shorter delay, significantly steeper slope and shorter rise time. Combining the figures in Table $\Pi$ with the TBP observations and the similarity of the nerve responses to quinine (shown in Figures 1 and 2) and tannin (not shown), we conclude that aspartame not only lacks sweetness to E.mongoz and M.murinus but that it might taste bitter. However, we want to stress that these conclusions are tentative. Single fiber recordings would have carried the analysis further, provided taste fibers of E.mongoz and M.murinus show a similar high specificity as we have seen in higher primates. However, because of difficulties in obtaining animals and the risk involved with surgery, this was never attempted.

\section{Gymnemic acid and miraculin}

With regard to gymnemic acid and miraculin, the results here corroborate earlier findings, both electrophysiological (Hellekant and van der Wel, 1989) and behavioral (Glaser $e t$ al., 1984). The results are similar to those observed in other non-hominoidea species (Hellekant 1975; Hellekant and Gopal, 1976; Hellekant, 1977; Hellekant and Roberts, 1983). They present further support for the idea that the sweet abolishing effect of gymnemic acid is limited to the hominoidea and the sweet enhancing effect of miraculin to the Simiae, thus strengthening our earlier conclusions on the phylogeny of the sense of taste in primates.

\section{Acknowledgements}

The authors are indebted to Mr. A.Tsang for statistical analysis; Drs M.Perret and A.Petter-Rousseaux for the use of the animals; Dr M.E.Hendrick, Pfizer for alitame; and the NutraSweet Company and NIH AA9391 for financial support.

\section{References}

Brennan,T.M. and Hendrick,M.E. (1983) Branched amides of L-aspartyl-D-amino acid dipeptides. US Patent $4,411,925$.

Brouwer,J.N., Glaser,D., Hard af Segerstad,C., Hellekant,G., Ninomiya, Y. and van der Wel,H. (1983) The sweetress-inducing effect of miraculin; behavioral and neurophysiological experiments in the thesus monkey (Macaca mularta). J. Physiol. (Lond), 337, 221-240.

Diamant,H., Hellekant,G. and Zotterman, Y. (1972) The effect of miraculin on the taste burds of man, monkey and rat. In Schneier,D. (ed.), Olfaction and Taste IV. Wissenschaftiche Verlagsgesellschaft MBH, pp. 241-244.

Glaser,D. and Hellekant,G. (1977) Verhattens und Elektrophysiologische Experimente über den Geschssmackssinn eines Primaten. Folia Primatol, 28, 43-51.

Glaser,D., Hellekant,G., Brourwer,J.N. and van der Wel,H. (1978) The taste responses in primates to the proteins thaumatin and monellin and their phylogenetic implications. Folia Primatol, 29, 56-63.

Glaser,D., Hellekant,G., Brouwer,J.N. and van der Wel,H. (1984) Effects of gymnernic acid on swet taste perception in primates. Chem. Senses, 8, 367-374.

Glaser,D., van der Wel,H., Brouwer,J.N., DuBois,G.E. and Hedlekam, G. (1992) Gustatory responses in primates to the sweetener aspartame and their phylogenetic implications. Chem. Senses, 17, 325-335.

Hellekant,G. (1975) Different types of sweer receptors in mammals. In Denton,D. and Coghlan,J.P. (eds), Olfaction and Taste V. Academic Press, pp. 15-21.

Hellekam,G. (1977) Effects of miraculin and gymnemic acid in the Rhesus monkey (Macaca mulanta). In Katsuki,Y., Sato,M., Takagi,S.F. and Oomura,Y. (ods), Food Intake and Chemical Senses. University of Tokyo Press, Tokyo, pp. 201-210.

Hellekant,G. and Gopal,V. (1976) On the effects of gymnemic acid in the hamster and rat. Acta Physioh. Scand. $98,136-142$. 
Hellekant,G. and Ninomiya, Y. (1991) On the taste of umami. Physiol. Behav., 49, 922-934.

Hellekant,G. and Roberts, T.W. (1983) Study of the effect of gymnemic acid on taste in hamster. Chem. Senses, 8, 195-202.

Hellekan,G. and van der Wel,H. (1989) Taste modifiers and sweet proteins. In Cagan,R. (ed.), Neural Mechanisms of Taste. CRC Press, Boca Raton, FL, pp. 85-96.

Hellekant,G. and Walters,D.E. (1993) On the sweetness of five high-potency sweeteners in rats. In Birch,G. and Mathlouthi,M. (eds), Sweet Taste Reception. Parthenon Publishing Ld, 371-384.

Hellekant,G., Hagstrom,E.C., Kasahara, Y. and Zotterman, Y. (1974) On the gustatory effects of miraculin and gymnemic acid in monkey. Chem. Sens. Flawor, 1, 137-145.

Hellekant,G., Glaser,D., Brouwer,J.N. and van der Wel,H. (1976) Gustatory effects of miraculin, monellin and thaumatin in the Saguinus midas tamarin monkey studied with electrophysiological and behavioral techniques. Acta Physiol. Scand., 97, 241-250.

Hellekant,G., Aronson,T. and Karlbom,U. (1980) Neural (electro-physiological) methods in chemoreception research. J. Anim. Physiol. Anim. Nutrit., 11, (Suppl.) 21-26.

Hellekant,G., Glaser,D., Brouwer,J. and van der Wel,H. (1981) Gustatory responses in three prosimian and two simian primate species (Tupaua glus, Nycricebus coucang. Galago senegalensis, Callithrix jacchus jacchus and Saguinus midas niger) to six sweeteners and miraculin and their phylogenetic implications. Chem Senses, 6, $165-173$.

Hellekant,G., Hard af Segerstad, C., Roberts, T., van der Wel,H., Brouwer,J.N., Glaser,D., Hayes,R.J. and Eichberg,J.W. (1985) Effects of gymnemic acid on the chorda tympani proper nerve responses to sweet, sour, salty and bitter taste stimuli in chimpanzee. Acta Physiol. Scand, 124, 339-408.

Hellekant,G., Hard af Segerstad,C., Roberts,T.W. and van der Wel,H. (1987) Intralingual stimulation with sweet proteins in thesus monkey and rat. In Roper,S. and Atema,J. (eds), Olfaction and Taste IX. Ann. NY Acad. Sci., 510, 356-358.

Hellekant,G., DuBois,G., Geismann, T., Glaser,D. and van der Wel,H. (1990) Taste responses of chorda tympani proper nerve in the white-handed gibbon (Hylobates lar). In Döving,K. (ed.), Olfaction and Taste $X$. GCS A/S, Oslo, pp 115-132.

Helkkant,G., Walters,E., Culberson,C., DuBois,G., Nofre,C. and Tinti,J.M. (1991) Electrophysiological evaluation of sweeteners. In Walters,E., Orthoefer,F.T. and DuBois,G.E. (eds), Sweeteners: Discovery, Molecular design and Chemoreception. ACS Symposium Series 450. Amencan Chemistry Society, Washington DC, 290-301.

Hellekant,G., Hladik,C.M., Dennys, V., Simmen,B. and Glaser,D. (1993) On the relationship between sweet taste and seasonal body weight changes in a primate (Microcebus murinus). Chem. Senses, 18, $27-34$.

Higginbotham,J.D. (1983) In Grenby,T.H., Parker,K.J. and Lindley,M.G. (eds), Developments in Sweeteners 2. Applied Science Publishers, London, pp. 119-155.

Hladik,C.M. and Hladik,A. (1988) Sucres et 'faux sucres' de la foret equatorial: evolution et percepton des produits sucres par les populations foresteres d'Afrique. J. Agric. Trad. Botan. Affl, 35, 51-66.

Hough,L. and Khan,R. (1978) Intensification of sweetness. Trends Biochem. Sci., 3, 61-63.

Iyengar,B., Smits,P., van der Ouderas,F., van der Wel,H., van Brouwershaven,J., Ravestein,P., Richters,G. and van Wassenaar,D. (1979) The complete amino-acid sequence of the swet protein thaumatin I. Eur. J. Biochem. 96, 193-204.

Jakinovich,W. and Sugarman,D. (1989) Peripheral mechanisms of mammalian sweet taste. In Cagan,R. (ed.), Neural Mechanisms of Taste. CRC Press, Boca Raton, FL, pp. 85-96.

Kare,M.R. and Ficken,M.S. (1963) Comparative studies on the sense of taste. In Zotterman, Y. (od.), Olfaction and Taste, Pergamon Press, London, pp. 285-297.

Mazur,R.H., Schlatter,J.M. and Goldkamp,A.H. (1969) Structure - taste relationships of some dipepeides. J. Amer. Chem. Soc., 91, 2684.

Menco,B. Ph. M. and Hellekant,G. (1993) Ultrastructural evidence for a binding substance to the sweet tasting protein thaumatin inside taste-burd pores of thesus monkey foliate papillae. Microscop. Res. Tech., In press.

Murray,R.G., Murray,A. and Hellekant,G. (1972) Fine structure of taste buds of rat fungiform papillae. In Schneider,D. (ed.), Olfaction and Taste IV. Wissenschaftliche Verlagsgesellschaft MBH. Pp. 56-62.

Nowak,R.M. (1991) Walker's Mammals of the World. 5th edn., I, John Hopkins University Press, Baltimore and London, pp. 400-435.

Perret,M. (1985) Diurnal variations in plasma testosterone concentrations in the male lesser mouse lemur (Microcebus murinus). J. Reprod. Fert., 74, 205-213.

Petersen,S. and Muller,E. (1948) Über eine neuse Gruppe von Süsstoffen (On a new group of sweeteners). Chem. Ber., 81, 31. 


\section{G.Hellekant et al.}

Petter-Rousseaux,A. (1980) Seasonal activity rhythms, reproduction, and body weight variations in five sympatric nocturnal prosimians, in simulated light and climatic conditions. In Charles-Dominique,P., Cooper,H.M. and Hladik,A. (eds), Noctumal Malagasy Primates. Ecology, Physiology, and Behavior. Academic Press, New York, pp. 137-152.

Petter,J. and Petter-Rousseaux,A. (1979) Classification of the prosimian. In Doyle,G.A. and Martin,R.D. (eds), Strudy of prosimian behavior, Academic Press, New York, pp. 1-44.

Simmen,B., Hladil,C.M. (1988) Seasonal variation of taste threshold for sucrose in a prosiman species, Micracebus muninus. Folia Primatol., 51, 152-157.

Tattersall,I. and Schwartz,J.H. (1975) Relationships among the Malagasy lemurs. The craniodental evidence. In Luckett, W.P. and Szalay,F.S. (eds), Phylogeny of primates, Pienum Press, New York, pp. 299-312.

Tinti.J.-M. and Nofre,C. (1984) Synthetic Sweetners Fr. Demande FR 2,533,210; Chem. Abstr., 101, 152354k. Walters,D.E., Orthoefer,F.T. and DuBois,G.E. (1991) Sweeteners: Discovery, Molecular Design and Chemoreception. ACS Symposium series 450 . American Chemistry Sociey, Washington, DC.

van der Wel,H. and Bel,W.J. (1978) Structural investigation of the sweet-tasting proteins thaumatin and monellin by immunological studies. Chem. Senses, 3, 99-104.

van der Wel,H. and Bel,W.J. (1980) Enzymatic properties of the sweet-tasting proteins thaumatin and monellin after partial reduction. Eur. J. Biochem., 104, 413-418.

Received on November 23, 1992; accepted on February 9, 1993 